\title{
DETERIORAÇÃO DOS TERMOS DE TROCA E INDUSTRIALIZAÇÃO PROTEGIDA: O PIONEIRISMO DE SIMONSEN1
}

Carlos Henrique Lopes Rodrigues ${ }^{2}$

Vanessa Follmann Jurgenfeld ${ }^{3}$

Resumo: Importantes interpretações sobre a América Latina - a deterioração dos termos de troca no comércio internacional e a defesa da industrialização periférica, por meio do planejamento como meio de superação do subdesenvolvimento costumam ser consideradas originárias da Comissão Econômica para América Latina e Caribe (Cepal) e, mais precisamente, a Raúl Prebisch. A discussão feita por Roberto Simonsen no Brasil ainda é frequentemente ignorada. Simonsen escreveu sobre esses temas entre as décadas de 1920 e 1940. Neste período, seus textos sobre o Brasil trouxeram discussão similar a que traria posteriormente a Cepal. Para entender a importância de Simonsen neste debate, o artigo busca fazer uma comparação entre as suas ideias e a produção inicial da Cepal, especialmente o texto de 1949, assinado por Prebisch, intitulado "O desenvolvimento econômico da América Latina e alguns dos seus problemas principais".

Palavras-chave: Simonsen. Cepal. Deterioração dos Termos de Troca. Industrialização. Protecionismo.

\section{DETERIORATION OF THE TERMS OF TRADE AND PROTECTED INDUSTRIALIZATION: THE PIONEERISM OF SIMONSEN}

Abstract: Important interpretations of Latin America - the deterioration of the terms of trade and the defense of peripheral industrialization through protectionism as a mean of escaping underdevelopment - have usually been attributed to the Economic Commission for Latin America and the Caribbean (ECLAC) and, more precisely, to Raúl Prebisch. The discussions made by Roberto Simonsen in Brazil have been frequently ignored. Simonsen wrote about these themes between the 1920s and 1940s. During this period, his texts on Brazil brought a similar discussion ECLAC' studies would bring later. In order to understand the importance of Simonsen in this debate, the article seeks to compare Simonsen's production on these themes and the original production of ECLAC, notably the text of 1949, signed by Prebisch, entitled "The Economic Development of Latin America and its main problems".

Keywords: Simonsen. Eclac. Deterioration of Commodity Terms of Trade. Industrialization. Protectionism.

\footnotetext{
${ }_{1}$ Uma primeira versão deste artigo foi apresentada no XXIV Encontro Nacional de Economia Política, em junho de 2019.

${ }^{2}$ Universidade Federal dos Vales do Jequitinhonha e Mucuri (UFVJM), Departamento de Ciências Econômicas, Teófilo Otoni-MG, Brasil, chlrodrigues@yahoo.com.br, https://orcid.org/0000-0001-84195826

${ }^{3}$ Universidade Federal dos Vales do Jequitinhonha e Mucuri (UFVJM), Departamento de Ciências Econômicas, Teófilo Otoni-MG, Brasil, vfollmann@hotmail.com, https://orcid.org/0000-0003-03789695
} 


\section{DETERIORO DE LOS TÉRMINOS DE INTERCAMBIO E INDUSTRIALIZACIÓN PROTEGIDA: EL PIONERISMO DE SIMONSEN}

Resumen: Importantes interpretaciones sobre América Latina - el deterioro de los términos de intercambio en el comercio internacional y la defensa de la industrialización periférica, a través de la planificación como medio de superación del subdesarrollo - suelen ser atribuidas como originarias de la Comisión Económica para América Latina y el Caribe (Cepal y, más precisamente, a Raúl Prebisch. La discusión hecha por Roberto Simonsen en Brasil todavía es a menudo ignorada. Simonsen escribió sobre estos temas entre la década de 1920 y 1940 . En este período, sus textos sobre Brasil trajeron una discusión similar a la que traería la Cepal más tarde. Para entender la importancia de Simonsen en este debate en Brasil, el artículo busca hacer una comparación entre las ideas de Simonsen y la producción inicial de la Cepal, especialmente el texto de 1949, firmado por Prebisch, titulado "El desarrollo económico de América Latina y algunos de sus principales problemas".

Palabras clave: Simonsen. CEPAL. Deterioro de los Términos de Intercambio.la Industrialización. Proteccionismo.

\section{Introdução}

Embasa este artigo uma inquietação sobre se Roberto Simonsen, economista autodidata e industrialista brasileiro, poderia de fato ser entendido como um precursor de alguns debates que costumam ser creditados à Comissão Economia para América Latina e Caribe (Cepal) e ao economista argentino Raúl Prebisch. Referimo-nos à defesa da industrialização nacional; ao planejamento estatal, que incluiria proteção ao setor industrial para o desenvolvimento de países atrasados como o Brasil, e à tendência à deterioração dos termos de troca no comércio internacional de modo desfavorável a países produtores e exportadores de bens primários como os da América Latina.

Um dos poucos autores que reconheceram o legado de Simonsen e sua influência sobre o pensamento latino-americano foi Ricardo Bielschowsky, que em livro sobre o ciclo ideológico do desenvolvimentismo afirmou que a Cepal teria dado sequência ao trabalho de Simonsen, após sua morte. Coincidentemente, o ano da morte de Simonsen, 1948, foi o mesmo ano em que a Cepal foi criada. "Essa coincidência histórica teve sua importância na evolução do desenvolvimento da CEPAL: a CEPAL, organismo que ostentava a credibilidade da ONU, tornou-se o 
principal órgão a dar sequência imediata ao trabalho de legitimação que Simonsen vinha realizando através da Fiesp e da CNI"4 (BIELSCHOWSKY, [1988] 2000, p. 78).

A assertiva de Bielschowsky, curiosamente, porém, não foi usada pelo biógrafo de Prebisch, Edgard Dosman (2011), que não cita Simonsen como uma influência importante para Prebisch. A ausência de menção a Simonsen também deve ser notada no importante artigo de Love (1996), em que ele faz uma radiografia de alguns autores entre 1920 e 1940 que poderiam ter influenciado Prebisch. Love citou, entre outros, Werner Sombart, Gustav Cassel, Mihail Manoilescu, François Perroux, Charles Kindleberger e Hans Singer, mas em nenhum momento refere-se a Simonsen.

Apesar de Bielschowsky colocar Simonsen no debate, ele não chegou a aprofundar as comparações entre a análise de Simonsen para o Brasil e a de Prebisch $/$ Cepal ${ }^{5}$ para a América Latina sobre os temas propostos neste artigo, de modo a explorar as possíveis similaridades dessas interpretações no que diz respeito à deterioração dos termos de troca, à industrialização e ao protecionismo do setor industrial.

Simonsen preocupou-se em estudar o Brasil com escritos importantes entre os anos de 1920 e 1948. Sua interpretação baseava-se na análise da história econômica do país ${ }^{6}$, sendo para ele fundamental "o estudo profundo de nossa evolução, no intuito de alcançar as soluções mais consentâneas com as nossas realidades" (SIMONSEN, 1943, p. 16).

Suas pesquisas resultaram em 1937 no livro "História Econômica do Brasil". A importância desta publicação é evidenciada com a seguinte afirmação de outro relevante pensador brasileiro, Celso Furtado: "Sem a obra de Roberto Simonsen eu nunca teria escrito Formação Econômica do Brasil7. É interessante lembrar que Simonsen reuniu um material riquíssimo sobre o período colonial brasileiro [...].

\footnotetext{
${ }^{4}$ Apesar de reconhecer o legado de Simonsen, Bielschowsky (2000, p. 78), contudo, entende que a Cepal representou um avanço em relação a Simonsen porque "forneceu um poderoso instrumental analítico antiliberal, que foi parcialmente incorporado pelos desenvolvimentistas da área privada e integralmente incorporado pela maioria dos desenvolvimentistas nacionalistas do setor público".

${ }^{5}$ Em razão de a interpretação de Prebisch e da Cepal como um todo se misturar desde o início da Comissão até 1963, quando Prebisch deixou a Cepal para trabalhar na Unctad, optou-se em várias passagens deste artigo pelo uso da denominação "Prebisch/Cepal".

${ }^{6}$ Simonsen ajudou a fundar a Escola Livre de Sociologia e Política em 1933, na qual era responsável pela disciplina história econômica do Brasil.

${ }^{7}$ Formação Econômica do Brasil foi a principal obra publicada por Celso Furtado, a primeira edição é de 1959, tendo sido traduzida para vários idiomas. Ver; Furtado ([1959] 1984).
} 
Quem quiser pensar o Brasil dessa época deve partir dele" (FURTADO apud VIEIRA, 2004, p. 24).

Prebisch iniciou seus escritos direcionados primeiramente ao estudo da economia argentina. Estes também ocorreram entre a década de 1920 e o início dos anos 1940 - antes da criação da Cepal, em 1948. A sua mais importante publicação, sistematizando o seu pensamento crítico ${ }^{8}$, porém, só ocorreu em 1949. Tratou-se do artigo "O desenvolvimento econômico da América Latina e alguns de seus problemas principais", assinado por ele ainda enquanto consultor da Cepal e apresentado na Conferência de Havana $^{9}$, ficando esta obra conhecida como a primeira grande síntese do pensamento da Cepal e como seu "Manifesto"10.

Este artigo busca uma comparação entre os argumentos de Simonsen sobre os temas já referidos e os de Prebisch/Cepal. Para dar conta do seu objetivo, o artigo tratará na sua primeira parte da defesa do setor industrial, abordando a importância do Estado em Simonsen para o avanço da industrialização no Brasil, e em seguida, como foram abordados esses mesmos temas nas teses iniciais de Prebisch/Cepal sobre América Latina. Na sua segunda parte, será debatida a deterioração dos termos de troca nessas duas concepções. Por fim, serão feitas algumas considerações sobre essas interpretações.

\section{A defesa do setor industrial}

\subsection{A interpretação de Simonsen}

Desde a década de 1920, Simonsen tratou a indústria como um "fator de riqueza", fundamental para a melhoria dos salários e do consumo. Ele basicamente a entendia como agente de um processo civilizatório. Em suas palavras,

a grande indústria, por toda a parte do mundo em que se instala, traz como corolário a melhoria dos salários, o barateamento relativo do produto, o enriquecimento social e o aumento da capacidade do

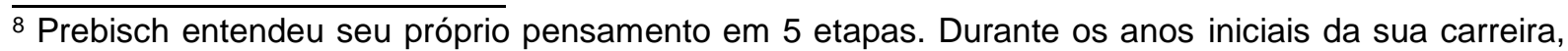
Prebisch adotou a interpretação ortodoxa da economia. O seu pensamento crítico foi construído mais tarde, sendo este também o período de constituição da Cepal. Ver: Dosman (2011) e Prebisch (1987). ${ }^{9}$ A Conferência de Havana foi o primeiro teste internacional da Cepal, dada a descrença com que a Comissão foi criada e os questionamentos do próprio governo norte-americano sobre sua necessidade diante da existência de outro organismo internacional na América Latina, como a Organização dos Estados Americanos (OEA). Os Estados Unidos tentaram encerrar os trabalhos da Cepal poucos anos após a sua criação. Sobre essa polêmica atuação dos Estados Unidos, ver: Furtado (1991).

10 Hirschman (1967) foi quem denominou esta síntese como "Manifesto da Cepal".
} 
consumo. Traz ainda mais, como consequência, a intensificação das relações comerciais, dos meios de transportes e a marcha vitoriosa da civilização. O Parque Industrial brasileiro só pode portanto concorrer para o enriquecimento do Brasil $^{11}$ (SIMONSEN, [1928] 1973, p. 57-58).

A indústria brasileira deveria se desenvolver em paralelo ao crescimento da agricultura. Os Estados Unidos, para ele, poderiam ser usados como um parâmetro para o Brasil, porque eram o exemplo de país que entendeu a importante relação entre os dois setores para o desenvolvimento econômico. Além disso, para garantir as atividades industriais em pleno funcionamento, primeiramente os norteamericanos preocuparam-se em expandir o seu mercado interno, amparando-o por meio de medidas protecionistas e pela elevação da renda nacional.

No Brasil, na avaliação de Simonsen, não havia essa percepção da "harmonia" que deveria ocorrer entre as duas atividades e nem sobre a proteção necessária ao desenvolvimento industrial, principalmente por meio da garantia do mercado interno para o consumo da produção industrial local. Simonsen julgava imprescindível que o país realizasse uma política protecionista, que, ao favorecer o desenvolvimento industrial, traria consigo o aumento da renda. Ampliar a renda nacional, por sua vez, funcionaria como uma condição para o próprio desenvolvimento industrial futuro do Brasil.

Ainda durante a década de 1920, Simonsen criticou a defesa da agricultura em detrimento da atividade industrial no Brasil. Para ele, era falha a argumentação de que deveriam ser respeitadas as "vantagens naturais", como chegaria a defender Eugênio Gudin ${ }^{12}$, pois isso condenaria o país a voltar à situação de "colônia". No Brasil, os que combatiam o desenvolvimento industrial em prol de que o país focasse em uma suposta vocação agrícola o faziam, segundo ele, em geral, a partir de cinco acusações:

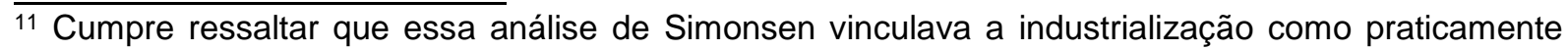
um sinônimo de desenvolvimento. Tratava-se de uma argumentação bastante entusiasta do processo industrial brasileiro a partir de experiências em outros países.

12 Ao contrário de Simonsen, Gudin era defensor da teoria das vantagens comparativas ricardianas e entendia que o Brasil deveria focar-se em produção agrícola e não no setor industrial. Simonsen e Gudin, sustentando argumentações opostas, travaram grandes debates sobre as maneiras de o Brasil alcançar um desenvolvimento econômico, suas divergências ficaram evidentes no I Congresso Brasileiro de Economia em 1943 e posteriormente na Controvérsia do Planejamento Econômico, quando, no Conselho Nacional de Política Industrial e Comercial, Simonsen ficaria responsável por fazer uma proposta sobre a política econômica que o Brasil deveria seguir no pós-Segunda Guerra. Seu relatório foi encaminhado para o parecer de Gudin, redundando em réplica por parte de Simonsen e em uma tréplica de Gudin. Ver: Rodrigues $(2005 ; 2018)$.
} 
a) que a indústria brasileira é em grande parte artificial, pois importa grande porção de matéria-prima do estrangeiro;

b) que não contribui para o enriquecimento do Brasil;

c) que, vivendo sob tarifas protecionistas produz caro, encarecendo sobremodo a vida da população;

d) que, atraindo braços à cidade, perturba a mão-de-obra do trabalho agrícola;

e) que constitui um monopólio em favor de meia dúzia de brasileiros, em detrimento de milhões de habitantes (SIMONSEN, [1928] 1973, p. 56).

Tais argumentos eram rebatidos por Simonsen ([1928] 1973) da seguinte forma: levando-se em consideração que uma indústria é tida como artificial ou não, de acordo com a porcentagem de matéria-prima importada na sua produção, os dados estatísticos demonstravam que no Brasil a participação dessas matériasprimas no processo produtivo era muito inferior à da Inglaterra $^{13}$, e naquele país jamais se ousou falar na existência de indústria artificial.

Quanto à acusação do abuso do regime protecionista no Brasil, Simonsen argumentou que, se a tarifa protecionista era alta, isso se devia às necessidades do fisco e não propriamente a uma política de proteção à indústria. Tanto isso era verdade que as tarifas incidiam indiscriminadamente, encarecendo vários produtos de importação, inclusive os que seriam necessários ao processo produtivo da indústria, como os insumos básicos. Tratava-se de uma política contrária a que defendia Simonsen. Para ele, "uma política protecionista organizada para o desenvolvimento das indústrias desonera as matérias-primas, pouco grava os produtos semi-industrializados, fazendo incidir os impostos aduaneiros principalmente sobre os produtos manufaturados" (SIMONSEN, [1928] 1973, p.58). Em outras palavras, seria uma política econômica que impediria uma grande concorrência de produtos importados já acabados sobre uma indústria nacional ainda pouco desenvolvida.

Simonsen ([1928] 1973) também não concordava que o custo de vida no Brasil estivesse se elevando devido ao regime alfandegário, uma vez que, para ele, o Brasil foi um dos raros casos de países pouco afetados pelo encarecimento do

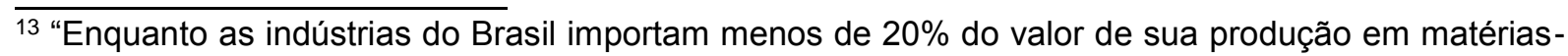
primas, a Inglaterra importa $65 \%$ [...]. O industrialismo na Inglaterra teve o seu grande desenvolvimento com o monopólio que soube criar de abastecimento industrial às suas colônias. $\mathrm{A}$ riqueza da Inglaterra, o seu poder político, o seu prestígio mundial, estão intimamente ligados às suas indústrias [...]" (SIMONSEN, [1928] 1973, p. 57).
} 
custo de vida no pós-Primeira Guerra Mundial, não tendo este ultrapassado 6\%. Dado que "no consumo médio por cabeça no Brasil, os produtos industriais representam $30 \%$ dos valores consumidos [...], de modo que admitindo um encarecimento médio de $20 \%$ sobre a generalidade dos produtos industriais, nunca onerariam em mais de $6 \%$ o custo médio de vida" (SIMONSEN, [1928] 1973, p. 59).

Contrariamente aos que acusavam a indústria também de retirar os trabalhadores do campo, supostamente contribuindo assim para o processo inflacionário, Simonsen concluía que a distribuição da mão de obra, nas diferentes atividades, mostrava que se havia escassez de trabalhadores na agricultura essa deficiência não se devia à indústria. Utilizando dados estatísticos do censo de 1920 , ele destacou que "na indústria em geral se encontravam apenas $3,8 \%$, e na indústria fabril pouco mais de 1\% [dos trabalhadores brasileiros]" (SIMONSEN, [1928] 1973, p. 59).

Nos seus escritos da década de 1930 e ao estudar a história econômica de outros países, Simonsen (1935) explicitava que as nações já industrializadas conquistaram seu desenvolvimento à custa do protecionismo. Diante disso, entendia que era inconcebível que o Brasil abrisse mão do protecionismo. Na história da industrialização dos países desenvolvidos houve uma série de políticas restritivas, como na França e na Inglaterra, além dos Estados Unidos.

Sobre a França, Simonsen (1935) entendia que a sua política comercial ao longo dos séculos XIX e XX foi protecionista, sendo liberal apenas em determinados momentos, uma vez que rapidamente via a necessidade de voltar a adotar uma política aduaneira protecionista. A França fora protecionista até 1860 . Adotou por alguns poucos anos o liberalismo e já em 1881 instituíra novamente o protecionismo. No período de 1918 a 1927, para compensar as desvalorizações de sua moeda, a França criou sobretaxas ad valorem aos produtos importados e, em 1926, os direitos aduaneiros sofreram duas majorações na ordem de $30 \%$ cada uma. Além disso, o governo francês evitava aceitar a cláusula de nação mais favorecida ${ }^{14}$ em seus

\footnotetext{
${ }^{14}$ A cláusula da nação mais favorecida fazia parte de tratados de reciprocidade, contendo condições jurídicas e teoricamente iguais para ambas as partes contratantes. Aceitar essa cláusula significava que os países com economias mais frágeis nas relações comerciais com países desenvolvidos sairiam prejudicados, uma vez que abririam mão de proteger sua economia e de tentar produzir internamente mercadorias industrializadas. Para Simonsen ([1948], 1951, p. 63), essa cláusula acarretava, "de fato, sob o ponto de vista econômico, uma progressiva vassalagem da nação menos aparelhada à mais poderosa". No caso da França, o que Simonsen queria chamar a atenção era que,
} 
tratados comerciais com outros países de industrialização mais avançada. Contudo, a partir de 1927, voltava a França a utilizar a cláusula de nação mais favorecida, mas com a Crise de 1929, de acordo com Simonsen (1935, p. 12), "julgou-se no dever imperioso de defender o seu mercado interno por novas medidas de proteção, e, assim, é que lançou mão de contingenciamentos, de sobretaxas, de depreciação de câmbio e de caixas de compensação".

Fugindo das teorias econômicas que propugnavam o liberalismo ${ }^{15}$, Simonsen (1935) interpretava, em síntese, que a França conseguiu, com a política protecionista adotada, posicionar-se de forma vantajosa no comércio internacional, principalmente por salvar parte da sua agricultura e muitas atividades industriais que se encontravam ameaçadas pela concorrência com outros países.

Em relação à Inglaterra, de acordo com Simonsen (1935, p. 13), houve proteção desde Oliver Cromwell, com os Atos de Navegação, em 1651. Além desses Atos, seguiram-se "numerosas leis estabelecendo o monopólio do comércio colonial; proibição e direitos proibitivos sobre importações de produtos manufaturados; privilégios e prêmios para a manufatura inglesa; proibição de importação de máquinas etc". Essa política protecionista inglesa utilizada foi até 1860, ou seja, por mais de 200 anos permitiu a ela uma posição de superioridade econômica perante o mundo, adotando a cláusula de nação mais favorecida. Posteriormente, a Inglaterra adotaria o liberalismo, tendo como referência os escritos de Adam Smith ([1776] 1983) e, sobretudo, de David Ricardo ([1817] 1988).

A política livre-cambista, entretanto, mostrou à Inglaterra a necessidade de voltar a usar medidas protecionistas em poucos anos, especialmente por conta da maior concorrência com a Alemanha e os Estados Unidos na produção de manufaturados. Com o início da Primeira Guerra Mundial, sua Comissão Econômica recomendou algumas medidas como: proteção às indústrias nacionais contra o dumping; manutenção de indústrias básicas; proteção por leis e direitos alfandegários das indústrias necessárias à defesa nacional; e o estabelecimento de um ministério para estudar formas de concessão de auxílio a alguns setores por parte do Estado (SIMONSEN, 1935). Posteriormente, "em 1931, estabeleceu direitos contra as importações anormais e, em maio de 1932, criou uma tarifa geral ad 
valorem de 10\%" (SIMONSEN, 1935, p. 15). Em 1933, adotou também uma política protecionista específica para os produtos agrícolas.

Já em relação aos Estados Unidos, Simonsen (1935) observou que, após sua independência, em 1776, houve raras exceções de períodos livre-cambistas neste país, de 1783 a 1789 e de 1833 até 1861, principalmente, por pressões do sul do país. Estas eram políticas influenciadas por Alexander Hamilton ${ }^{16}$, considerado precursor de Friedrich List $^{17}$, no que se refere ao protecionismo ${ }^{18}$. Os Estados Unidos assim tiveram logo a percepção de que primeiro seria necessário desenvolver tanto sua agricultura quanto sua indústria, garantindo inicialmente o mercado interno para seus produtos, para posteriormente ampliar sua participação no comércio internacional.

Um outro exemplo do protecionismo norte-americano se deu em 1933, quando o presidente Franklin Roosevelt promoveu a política do New Dea/ri , na tentativa de superar os problemas decorrentes da Crise de 1929. O New Deal criou, segundo Simonsen (1935, p. 16), "os grandes códigos norte-americanos de intervenção, em todas as suas modalidades, no comércio, na agricultura e na indústria", que, juntamente com a depreciação do dólar tinha a finalidade de permitir que as mercadorias norte-americanas concorressem no exterior em paridade com as mercadorias inglesas.

Esses exemplos foram usados por Simonsen para ilustrar políticas que deram certo naqueles países em diferentes períodos históricos e o quão distante o Brasil estava de medidas como essas. Como comparação, no Brasil, entre meados do século XIX (após a sua independência em 1822 e quando constituiu suas primeiras indústrias) e início do século XX (com o avanço da importância do setor industrial), a política mostrava-se muito mais liberal do que protecionista. Em vários governos, quando ocorria, o protecionismo era provisório ou "acidental".

Poucas medidas protecionistas, de fato, poderiam ser mencionadas entre 0 século XIX e o início do século XX no Brasil. Em 1844, o governo imperial colocou em vigor a Tarifa Alves Branco, que sobretaxava produtos importados, especialmente aqueles que já poderiam ser produzidos no país. Em 1889, também

\footnotetext{
16 Ver Hamilton ([1791] 1995)

17 Ver List ([1841] 1986).

18 List conviveu com Hamilton nos Estados Unidos e essa influência fortaleceu seus argumentos a favor do protecionismo. Ver: List ([1841] 1986).

19 Sobre o período histórico e a importância do New Deal, recomenda-se Hobsbawm (1995).
} 
houve um certo protecionismo com a inauguração do período Republicano brasileiro, quando o ministro da Fazenda do Governo Provisório Rui Barbosa promoveu uma política econômica conhecida por "encilhamento" que, além de crescimento industrial, caracterizou-se por uma fase de especulação e alta inflação no biênio 1890-91. Rui Barbosa inaugurou a tarifa-ouro, em que parte do imposto sobre importação era paga em ouro, atendendo às necessidades do Erário e, de alguma forma, das indústrias nacionais. Entre 1898 e 1902, no governo de Campos Sales, o ministro da Fazenda Joaquim Murtinho, apesar de iniciar uma campanha contra as indústrias nacionais, acusando-as de serem artificiais, segundo Simonsen ([1939] 1973, p. 19), "foi, porém, forçado a aumentar consideravelmente muitas taxas [de importação] e a adotar em larga escala a quota-ouro", situação que acabou promovendo algum protecionismo para as indústrias nacionais ${ }^{20}$.

Em 1939, Simonsen também reafirmaria a necessidade de haver um desenvolvimento industrial juntamente com o crescimento da agricultura no país. De um lado, a agricultura seria imprescindível para o fornecimento de alimentos e matérias-primas indispensáveis ao desenvolvimento industrial. $E$, de outro, 0 crescimento da agricultura também estaria vinculado ao desenvolvimento industrial, porque "o progresso da agricultura [iria], por seu turno, e cada vez mais, depender do aumento das indústrias, pelo crescimento do consumo das matérias-primas oriundas da terra" (SIMONSEN, [1939] 1973, p. 48).

Argumentações desse tipo também seriam reafirmadas na participação que Simonsen teve no I Congresso Brasileiro de Economia, realizado em 194321. Após esse Congresso, ele organizou e participou da I Conferência Nacional da Indústria, em 1944, e, em 1945, esteve na I Conferência das Classes Produtoras, defendendo as mesmas ideias.

No I Congresso Brasileiro de Economia, Simonsen (1943) explicitou em seu discurso a evolução econômica pela qual passava o Brasil naquele período da Segunda Guerra Mundial e a urgência da elevação da renda nacional para propiciar

\footnotetext{
${ }^{20}$ Simonsen ([1939] 1973) chegou também a citar que no primeiro governo de Getúlio Vargas houve proteção ao setor industrial, mas disse que esta não teve tanta efetividade. Ele mencionou a Reforma de Oswaldo Aranha, de 1934, por meio da qual a tarifa-ouro foi definitivamente extinta e substituída por impostos específicos e não ad valorem. Isso significou que as mercadorias importadas pelo país passariam a ter uma tributação fixa sobre o seu valor em moeda nacional. À medida que havia desvalorização da moeda nacional, essas tarifas diminuíam na mesma proporção, reduzindo-se assim gradativamente a proteção do setor nacional industrial contra as mercadorias importadas.

21 Ver: Anais... (1943; 1944; 1946).
} 
melhores condições de vida ao povo brasileiro ${ }^{22}$. Novamente, ele ressaltaria que a grande preocupação do governo nacional deveria ser a adoção de uma política industrial.

Em 1944, na I Conferência Nacional da Indústria, ele discutiria a necessidade de participação do Estado na economia, além do reaparelhamento industrial e do barateamento dos custos de produção.

Em 16 de agosto de 1944, Simonsen enviaria à Comissão Nacional de Planejamento Industrial e Comercial seu parecer intitulado "A Planificação da Economia Brasileira", cujo objetivo foi o de propor uma política econômica a ser seguida pelo Brasil no pós-guerra. Inicialmente, Simonsen evidenciara novamente a necessidade de o Brasil se industrializar, utilizando o trabalho do perito dos Estados Unidos, Lee Hagar, para elucidar as vantagens da indústria sobre a agricultura. Nesse trabalho, Hagar discorreria sobre os rendimentos individuais médios das pessoas que viviam em países industrializados, como os Estados Unidos, e em países de "economia vegetal", como a Índia e a China, chegando às seguintes conclusões:

Conforme se deduz do exame de rendimentos individuais de vários países, o americano médio possui recursos para consumir duas vezes mais produtos básicos que um francês ou alemão, quatro vezes mais que um russo, seis vezes mais que um japonês e dezoito vezes mais que um chinês ou um nativo da Îndia. Qualquer país com disponibilidades ilimitadas de energia, abundância de alimentos e fartos recursos em metais pode edificar uma economia muitíssimo superior, sob o aspecto material, à economia de civilizações "vegetais, tais como as da Índia e da China, dependentes como ainda são, de energia animal. Como resultado dessa superioridade, as nações industriais serão inevitavelmente conduzidas à posição de domínio mundial, no campo da economia, finanças e política internacionais" (SIMONSEN, [1944] 1977, p. 24).

Simonsen ([1944] 1977) embasaria suas propostas também em outro estudo elaborado pela Comissão de Fomento Interamericano, que explicitou o "enriquecimento ilusório" de várias Repúblicas da América Latina durante a Segunda Guerra Mundial. Nesse período, o aumento do preço dos produtos primários exportados foi o principal causador do superávit das balanças comerciais desses

\footnotetext{
22 Simonsen ainda ressaltou a relevância do I Congresso Brasileiro de Economia para o recém-criado Conselho Nacional de Política Industrial e Comercial. Ele foi presidente da Comissão Técnica denominada Produção Agrícola e Industrial.
} 
países e não seu desenvolvimento industrial. Para Simonsen, com o fim da guerra, haveria queda desses preços e, consequentemente, uma mudança nos resultados das balanças comerciais. Por isso era imprescindível que o governo adotasse planejamento e política protecionista para seu "reequipamento" após a Segunda Guerra Mundial.

Outro trabalho bastante utilizado por Simonsen em 1944 foi o efetuado pela Missão Cooke, que esteve no Brasil no segundo semestre de 1942, e, que, nesse contexto de guerra, preconizou uma política industrial para que, se a guerra continuasse durante muito tempo, o país tivesse condições de ajudar os Aliados (Estados Unidos, União Soviética, Grã-Bretanha, entre outros) de maneira mais intensa nos esforços de guerra. A Missão fez um diagnóstico dos problemas brasileiros e indicou os pontos fracos a serem imediatamente sanados para que 0 país pudesse avançar na sua industrialização:

1) a dependência da importação de petróleo, que utilizamos em larga escala em motores industriais, nos automóveis e até para a iluminação; 2) a importação de carvão mineral para os transportes e motores industriais; 3) a carência de metais especiais e equipamentos para novos empreendimentos e conservação dos existentes. Todas essas insuficiências foram motivos de agudas crises registradas na presente guerra (SIMONSEN, [1944] 1977, p. 26).

Apesar de Simonsen ([1944] 1977) reconhecer que nos últimos cinco anos ${ }^{23}$ teria ocorrido um crescimento industrial na economia brasileira, a renda nacional continuava muito baixa e precisava ser aumentada. Utilizando dados elaborados pelo Ministério do Trabalho, Simonsen afirmava ser a renda brasileira de 40 bilhões de cruzeiros e que esta renda deveria ser elevada para 160 bilhões, com o objetivo de fomentar o mercado interno e conter as possibilidades de intranquilidades sociais devido ao baixo poder de compra da população brasileira.

Um ano depois, a importância da industrialização brasileira foi novamente abordada por Simonsen (1945) sob 5 aspectos: i) reerguimento econômico nacional com o objetivo de elevar o padrão de vida da população; ii) exame das novas atividades criadas durante a Segunda Guerra Mundial; iii) amparo às indústrias

${ }^{23}$ É importante ressaltar que o relatório de Roberto Simonsen, entregue para análise do Conselho Nacional de Política Industrial e Comercial (CNPIC), é de 1944. Portanto, os últimos cinco anos a que se refere o autor diziam respeito a 1939-1944. 
criadas no contexto da guerra; iv) estudo sistemático do custo de produção da indústria brasileira, em comparação com a dos países industrializados e; v) necessidade de fixação de normas permanentes de política industrial.

Em 1945, na I Conferência das Classes Produtoras, realizada em Teresópolis (RJ), praticamente todas as recomendações da FIESP, entidade que Simonsen ajudou a criar e presidiu entre 1937 e 1945, foram aprovadas ${ }^{24}$. Essas sugestões seguiram as acatadas no I Congresso Brasileiro de Economia e na I Conferência Nacional da Indústria, basicamente os cinco pontos já citados.

\subsection{A interpretação de Prebisch/Cepal}

Um ano após a morte de Simonsen, em 1948 foi criada a Comissão Econômica para a América Latina e Caribe (Cepal) e, em 1949, surgiram as teses iniciais da Cepal, instituição sediada no Chile, comandada inicialmente por Miguel Cabañas e, em seguida, pelo argentino Raúl Prebisch. Este primeiramente foi consultor contratado pela Comissão e, posteriormente, em 1950, tornara-se seu secretário-executivo até 1963, quando deixaria a Cepal para trabalhar na Unctad.

As teses desenvolvidas pela Cepal nos seus anos iniciais difundiram-se pela América Latina, e especialmente no Brasil ${ }^{25}$. Uma das principais defesas pela Comissão e particularmente por Prebisch ([1949] 2000) era a da industrialização desses países para que superassem a dependência externa, o que receberia a denominação desenvolvimento hacia adentro.

Prebisch entendia que a industrialização por substituição de importações nessa região durante a Primeira Guerra Mundial e após 1930 era um caminho correto e já em curso em vários países, mas que deveria ser adotada como uma política deliberada pelos governos desses países para que, de fato, tivesse o sentido da superação do subdesenvolvimento.

A industrialização por substituição de importações não só auxiliaria o fortalecimento do mercado interno a partir de um setor industrial mais forte dentro

\footnotetext{
24 Ver: Ferraz (1945).

${ }^{25} \mathrm{~A}$ influência da Cepal se tornara tão expressiva a ponto de o diagnóstico e as recomendações da Comissão se irradiarem pelos governos da América Latina, ainda que com efeitos distintos. $\mathrm{Na}$ América Central e em Cuba suas ideias podiam reduzir a influência dos Estados Unidos sobre a região e por isso eram recebidas com excitação. No México, Prebisch era admirado, porém não convencia a todos. Já em outros países, como o Peru e a Colômbia, era ignorada a existência da Cepal nessa primeira fase. O Brasil e o Chile foram, contudo, os países onde as ideias da Cepal mais produziram efeitos (FURTADO, 1985).
} 
desses países, como também poderia modificar a inserção externa da América Latina, modificando os itens exportáveis. A industrialização era entendida como uma forma de possibilitar à região exportar também produtos industrializados, deixando de ser meramente uma área primário-exportadora, estabelecendo uma outra relação comercial com os países do centro do sistema, de modo a reduzir sua dependência e vulnerabilidade externas.

Assim como aparecia em Simonsen, acelerar a industrialização era praticamente sinônimo de desenvolvimento nacional. Entendia-se que a industrialização traria a melhoria das condições de vida da população latinoamericana em geral. Com ela, as economias primário-exportadoras romperiam uma relação subordinada que até então as caracterizou, sob a lógica de um desenvolvimento hacia afuera ${ }^{26}$, determinado pelo centro do sistema.

Na visão de Prebisch ([1949] 2000), o avanço da industrialização não era uma escolha, mas a única alternativa existente naquele período histórico para de fato haver crescimento por longo prazo e a superação do subdesenvolvimento na região:

\begin{abstract}
Em épocas passadas, antes da grande depressão, os países da América Latina cresceram ao serem impulsionados, de fora para dentro, pelo crescimento persistente das exportações. Nada nos autoriza a supor, pelo menos por enquanto, que esse fenômeno venha a se repetir com intensidade análoga, a não ser em casos muito particulares. Já não existe a alternativa entre continuar crescendo dessa maneira, vigorosamente, ou crescer para dentro, através da industrialização. Esta última passou a ser o modo principal de crescimento ${ }^{27}$ (PREBISCH, [1949] 2000, p.78).
\end{abstract}

Em termos mais específicos, a substituição de importações ajudaria a corrigir uma tendência à restrição externa, uma vez que os países subdesenvolvidos latino-americanos em geral lidavam com uma baixa elasticidade de demanda por produtos primários importados pelo centro. Isso ocorria porque, entre outros fatores, havia desenvolvimento tecnológico no centro de produtos sintéticos em substituição

\footnotetext{
${ }^{26}$ Desenvolver-se "para fora" significava, em outras palavras, ter a América Latina o papel de servir às necessidades do centro com seus bens primários, atendendo a necessidade do desenvolvimento dos outros países e não resolvendo o seu próprio subdesenvolvimento, a partir da industrialização se transformaria em um desenvolvimento "para dentro".

${ }^{27}$ Crescimento e desenvolvimento também eram usados como sinônimos. A discussão no pós-guerra sobre termos como o desenvolvimento havia recém-iniciado quando da escrita de Prebisch em 1949. Ver: Jurgenfeld (2018).
} 
aos produtos primários usados, por exemplo, em insumos do processo industrial. Além disso, conforme ocorria o aumento da renda da população no centro, haveria sempre uma demanda maior por produtos industrializados em detrimento aos produtos agrícolas. O mesmo ocorreria na periferia, conforme avançasse a renda nesses países ${ }^{28}$.

A industrialização por substituição de importações também modificaria a estrutura sobre a qual esses países haviam se formado, característica que vários autores cepalinos denominaram como "desequilíbrios estruturais"29. Entre os impactos importantes da aceleração da industrialização na região podem ser mencionados o fato de ela reduzir a vulnerabilidade externa desses países, porque eles importariam menos máquinas e equipamentos com o passar do tempo, exportariam mais e neste caso estariam menos vinculados à somente uma pauta de exportação de produtos primários, podendo também exportar produtos industrializados.

Além disso, a substituição de importações significaria maior incorporação de progresso técnico, efeitos que seriam positivos para o aumento da produtividade do setor industrial e agrícola. Conforme avançasse a industrialização haveria cada vez mais demanda ao setor agrícola, que também cresceria. A agricultura deveria inclusive acompanhar o crescimento do setor industrial para que o abastecesse com uma oferta adequada de insumo e de alimentos para a força de trabalho.

Na visão da Cepal, o progresso técnico, ao se desenvolver nos países latinoamericanos, por um lado, pouparia mão de obra (quando da colocação de máquinas novas em uma fábrica, por exemplo, reduzindo os empregados), mas criaria, por outro lado, novas oportunidades de empregos na indústria produtora de máquinas, por estimular um Departamento I internamente (departamento produtor de bens de capital, que estaria inclusive desenvolvendo equipamentos de acordo com as reais necessidades das economias latino-americanas). Havendo uma adequada

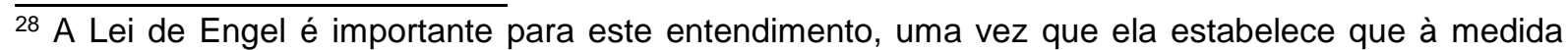
que o indivíduo melhora de padrão de vida, isto é, sua renda real, reduz-se a cota-parte de sua despesa destinada à alimentação, com isso, ele passa a gastar uma maior proporção de sua renda com outros produtos que não os agrícolas, ou seja, com os industrializados.

29 Entre diversos autores que mostraram os desequilíbrios estruturais podem ser citados por exemplo: Aníbal Pinto e Noyola Vásquez. Este último mostrou inclusive como o problema da inflação tinha como causa os desequilíbrios estruturais, entendendo, portanto, a inflação nesses países não como um fenômeno monetário, mas sim estrutural. Ver: Pinto ([1970] 2000) e Vásquez ([1957] 2000).
} 
legislação social, a Cepal entendia que ocorreriam melhorias também nos salários de maneira geral.

Ao desenvolver-se "para dentro", por meio da industrialização por substituição por importações, os países não deveriam se fechar, sem comércio exterior ${ }^{30}$ e sem capital estrangeiro. Prebisch ([1949] 2000) entendia ser necessário ampliar o comércio exterior latino-americano, sob novas bases, ou seja, com exportação de bens industrializados e não só produtos primários. Haveria, em suma, uma mudança na pauta exportadora e na de importação. Sobre este último aspecto, os países latino-americanos também deveriam reduzir a importação de itens de luxo do centro para o consumo suntuário de uma minoria burguesa e focar na importação daquilo que seria necessário ao avanço da sua industrialização.

Nas palavras de Prebisch, isso significava mudar a relação de comércio exterior da América Latina e a importância que havia no setor externo para seu próprio crescimento. Ou seja, a região deveria não mais crescer à custa do comércio exterior, dele dependendo, mas saber "extrair, de um comércio exterior cada vez maior, os elementos propulsores do [seu] desenvolvimento econômico" (PREBISCH, 1949 [2000], p. 73).

Ao capital estrangeiro, na visão de Prebisch, deveria ser permitida a sua entrada nesses países para colaborar com a industrialização e o progresso técnico. Este capital deveria estar sob coordenação do Estado nacional, de forma a realizar os investimentos necessários, de fato, para o processo de desenvolvimento econômico dos países da América Latina. O capital estrangeiro poderia inicialmente atuar em setores que reduzissem a necessidade de importação da região, por exemplo. A ideia de Prebisch é que o Estado controlasse esse capital ${ }^{31}$.

Neste sentido, pode-se dizer que desenvolver-se "para dentro" significava os países terem políticas internas voltadas para si em primeiro lugar e conseguir uma espécie de solidariedade dos países centrais em "aceitar" suas transformações estruturais na direção do desenvolvimento nacional.

\footnotetext{
$\overline{30}$ Sobre a importância do comércio exterior, Prebisch defendeu inclusive o aumento dele, e como estratégia para uma melhor posição da América Latina em relação aos países centrais propôs a criação do Mercado Comum Latino-americano. Ver: Prebisch ([1957] 2000). Uma boa síntese sobre a interpretação de Prebisch a respeito do comércio exterior pode ser encontrada em Braga (2009).

31 Ver: Prebisch (1970) e Gurrieri (1982).
} 
Hirschman (1967) entendeu, de forma limitada32, que a Cepal mostrava com essas ideias que o atraso latino-americano se devia ao sistema de comércio internacional e às doutrinas de livre comércio. Assim, a solução para sair dessa situação seria corrigir os problemas do comércio internacional por meio de intervenção deliberada do Estado em processos de industrialização em curso já na região. Na prática, isso se traduziria na promoção da industrialização com protecionismo ${ }^{33}$.

Industrializar-se adequadamente dependia de haver planejamento, tema que sempre esteve na pauta da Cepal, mas que entrou mais detidamente na agenda da Comissão em 1955 ${ }^{34}$. Prebisch considerava o planejamento estatal como algo compatível com o interesse do setor privado e do mercado em geral e justificaria anos depois o porquê da sua defesa do planejamento da seguinte forma:

Los cambios estructurales inherentes a la industrialización requieren racionalidad y visión en la política gubernamental e inversiones en infraestructura para acelerar el crecimiento económico, obtener una relación adecuada entre la industria y la agricultura y otras actividades, y reducir la vulnerabilidad externa de la economía. Por lo tanto, había fuertes razones en favor de la planeación. También era importante la necesidad de intensificar la tasa de acumulación interna de capital mediante incentivos apropiados y otras medidas de política económica (PREBISCH, 1987, p. 347).

Prebisch (11949] 2000) partia da ideia de que para haver industrialização era preciso resolver o problema da formação de capital na América Latina e isso não se fazia por meio das livres forças do mercado. Basicamente, havia escassez de investimentos, sobretudo em bens de capital na região, que pudessem fomentar a industrialização, e para que esse quadro se modificasse era fundamental haver uma política de Estado.

\footnotetext{
32 É preciso dizer que Prebisch ([1949] 2000) não se limitou a discutir o comércio internacional (ainda que este fosse bastante importante na sua teorização), mas o problema maior do subdesenvolvimento latino-americano. Hirschman (1967) reduziu a interpretação de Prebisch.

${ }_{33} \mathrm{O}$ protecionismo para o setor industrial foi defendido por Prebisch/Cepal desde os textos iniciais, mas este ficaria mais evidente nos anos 1960. Ao constatar os rumos equivocados de alguns processos de industrialização em países latino-americanos Prebisch (1963) tratou do problema de insuficiência dinâmica e tornou-se mais convencido de que o desenvolvimento dessa região não ocorreria de maneira espontânea, devendo ser uma política deliberada do Estado promover a industrialização. Ele mostrou esse seu ponto de vista sinteticamente ao escrever também o prefácio da obra de Rodríguez (1981). Ver: Prebisch (1950 [1982]) e Couto (2007).

34 Ver: Cepal ([1955] 2000).
} 
A industrialização, contudo, "não [constituía] um fim em si, mas [era] o único meio de que estes [países dispunham] para ir captando uma parte do fruto do progresso técnico e elevando progressivamente o padrão de vida das massas" (PREBISCH, [1949] 2000, p. 72). Como ele destacara:

Se, através do progresso técnico, conseguirmos aumentar a eficácia produtiva, por um lado, e se a industrialização e uma legislação social adequada forem elevando o nível do salário real, por outro, será possível irmos corrigindo gradativamente o desequilíbrio da renda entre os centros e a periferia, sem prejuízo dessa atividade econômica essencial (PREBISCH, [1949] 2000, p. 78).

Advogar em prol da industrialização não correspondia, deve-se ressaltar, a defender o interesse de uma classe, a burguesia industrial, mas sim era entendida por Prebisch como a defesa do desenvolvimento nacional ${ }^{35}$.

\section{A deterioração dos termos de troca}

\subsection{A interpretação de Simonsen}

Simonsen já sinalizava na década de 1920 para a tendência à deterioração dos termos de troca, que prejudicava significativamente o Brasil, país que estava focado em exportação de produtos agrícolas, e beneficiava os países industrializados. Por isso ele acusava que

os brasileiros que combatem a implantação e disseminação das indústrias no país, fazem consciente ou inconscientemente obra a favor das nações estrangeiras, interessadas na conquista dos nossos mercados, trabalhando para que retrogrademos à posição de colônia dos produtos estrangeiros à mercê ainda de um bloqueio econômico em caso de Guerra (SIMONSEN, [1928] 1973, p. 55).

Simonsen avançou nesta análise em 1943, ao ressaltar que se manter enquanto produtor e exportador de "produtos coloniais" caracterizaria uma posição frágil do Brasil no comércio internacional, uma vez que a demanda para essas mercadorias seria inelástica e os seus preços sujeitos a oscilações. Além disso, esse

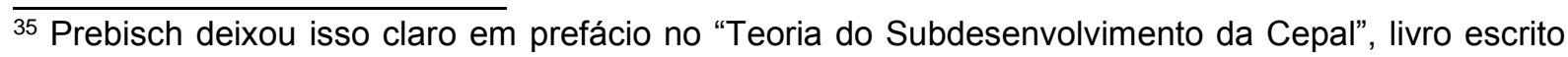
por Octávio Rodríguez (1981). Este autor uruguaio, membro da própria Comissão, fez críticas à Cepal. Entre elas, apontou o fato de que ao defender a industrialização latino-americana a Cepal estava realizando a defesa de uma única classe, a da burguesia industrial. As críticas a Rodríguez foram respondidas por Prebisch no próprio livro, uma vez que foi convidado para escreveu o seu prefácio.
} 
tipo de intercâmbio favoreceria os países desenvolvidos, produtores e exportadores de bens industrializados, altamente rentáveis.

Quando se realizam tratados de comércio entre uma nação fortemente industrializada, e outra, em que predominam, como artigos de exportação, os chamados "produtos coloniais", promovese de fato a troca de produtos fracamente remunerados, por outros altamente recompensados. Mesmo que se equilibrem, em valor monetário, as balanças de comércio e de pagamentos entre essas nações, o intercâmbio realizado favorece, sem dúvida, o país mais industrializado (SIMONSEN, [1943] 1973, p. 290).

Anos depois, concluiria que essa relação fazia com que os países industrializados possuíssem altos níveis de renda, e os agrícolas, como o Brasil, baixos níveis de vida. Além disso, verificava que era "elevada a participação dos primeiros no comércio mundial, enquanto os segundos, que, paradoxalmente, [viviam] à base de seu comércio exterior, [exerciam] pequeno papel no intercâmbio internacional" (SIMONSEN, [1948] 1951, p. 63).

Como forma de explicitar essa inferioridade dos países agrário-exportadores em relação aos países industrializados no comércio internacional, Simonsen chegou a defini-la como uma "situação desvantajosa nos termos de troca":

a situação do intercâmbio dos países exportadores de manufaturas e países exportadores de produtos primários impõe a estes uma situação desvantajosa nos termos de troca. Os produtos primários, de uma maneira geral, são inelásticos e, inversamente, os produtos manufaturados têm uma alta elasticidade. A evolução dos preços de uns e outros produtos mostra disparidades. As flutuações dos níveis de preços atingem mais duramente os produtos primários do que os manufaturados, depreciando os termos de troca dos países exportadores dos primeiros [produtos primários]. Por outro lado, os preços dos produtos primários, via de regra, não são influenciados pelos países produtores, mas são ditados pelos próprios países manufatureiros (SIMONSEN [1948] 1951, p. 63, grifos nossos).

Observa-se que Simonsen, neste trecho, além de citar novamente a diferença na questão da demanda inelástica por produtos agrícolas frente à demanda elástica de produtos manufaturados - o que estava presente na argumentação da Lei de Engel -, também destacava a dominação dos países industrializados sobre os demais, uma vez que estes ditavam os preços que pagariam pelos produtos primários dos países não industrializados. 


\subsection{A interpretação de Prebisch/Cepal}

A principal análise de Prebisch/Cepal sobre a deterioração dos termos de troca para América Latina foi publicada em 1949 no texto "O desenvolvimento econômico da América Latina e alguns de seus problemas principais" 36 .

Prebisch ([1949] 2000) partiu do estudo dos ciclos econômicos e entendeu que havia uma permanência da deterioração dos termos de troca para a periferia latino-americana como um todo na troca de seus produtos primários pelos produtos industrializados dos países do centro. De 1870 até a Segunda Guerra Mundial, a tendência da relação de preços no comércio internacional se moveu de forma contrária aos interesses da periferia. Como resultado, os frutos do progresso técnico ocorrido no centro do sistema não eram distribuídom de maneira equitativa pelo globo, ficando a periferia com pouca ou quase nenhuma parte disso.

Isso ocorria porque na hora em que o país central incorporava progresso técnico em seus produtos, no momento de expansão do ciclo econômico, ele subia o preço da mercadoria na qual foi realizado o progresso técnico e não o reduzia, mesmo que isso tivesse resultado em um aumento de sua produtividade e em uma redução de seus custos de produção. Na prática, aliás, na fase ascendente do ciclo, subia-se o preço, porque o empresário, dono do progresso técnico, queria lucros sempre de maneira ampliada, e sofria no centro uma pressão altista de salários, dado o pleno emprego. Prebisch ([1949] 2000) identificou que havia, portanto, um aumento da renda (lucros e salários) nos países centrais na fase ascendente dos ciclos e que, contrariamente ao que era esperado pela teoria convencional (neoclássica), não havia uma redução significativa dessa renda na fase descendente.

$\mathrm{Na}$ fase descendente do ciclo econômico dos países centrais, a periferia, inclusive, perdia ainda mais. Seus produtos primários tinham menos demanda, com preços em queda, enquanto a produção do centro seguia com preços altos. Deste modo, os países subdesenvolvidos, ao longo do tempo, por meio das relações de troca com os países centrais, pagaram pelos produtos industrializados muito mais do

\footnotetext{
${ }^{36}$ Sobre características e alguns efeitos do comércio internacional, Prebisch chegou a escrever alguns textos entre os anos 1920 e 1930, que antecipavam ideias que apareceriam em 1949. Estes primeiros escritos eram restritos à Argentina, sem ainda uma constatação mais robusta e sistematizada dos efeitos da deterioração dos termos de troca (O'CONNELL, 2001).
} 
que receberam por seus produtos primários, de maneira que sustentaram padrões de vida crescentes no centro.

Uma forma de Prebisch deixar isso evidente foi exemplificar que entre 1946 e 1947 só era possível comprar 68,7\% de mercadorias industrializadas em relação à mesma quantidade que era adquirida com produtos primários nos anos 1876 e 1880. Portanto, tratava-se de permanente aprofundamento da deterioração dos termos de troca para a periferia no comércio internacional ${ }^{37}$. Dessa forma, Prebisch ([1949] 2000) mostrou que os países de produção primária não conseguiam ou tiravam muito pouco benefício do progresso técnico dos países centrais.

Portanto, existia uma falha na teoria convencional que defendia o livre comércio e a teoria das vantagens comparativas ricardianas como benéfica a todos os países. Tratava-se, na verdade, de algo positivo circunscrito, sobretudo, aos países centrais.

A ideia por trás dessa concepção a qual Prebisch ([1949] 2000) criticava era a de que quando aumentasse o progresso técnico nos centrais, em razão da indústria que possuíam, esses países comprariam mais matérias-primas dos países periféricos. Ao comprar mais matérias-primas, aumentariam a demanda por bens primários e isso refletiria em subida dos preços dos primários, uma vez que há uma demora entre a demanda e a produção de itens que dependem de um ciclo agrícola para produção e colheita. Em outras palavras, haveria mais demanda em relação a uma oferta inelástica, logo, os preços dos primários cresceriam. Neste sentido, os periféricos, apesar de não desenvolverem a tecnologia, teriam acesso aos frutos também do aumento do progresso técnico ocorrido nos centrais pelos preços mais favoráveis dos seus produtos no comércio internacional.

Além desta invenção, a teoria neoclássica entendia que os bens industriais que recebiam mais tecnologia e que eram do interesse dos países periféricos supostamente teriam seus preços reduzidos. Isso porque o progresso técnico seria responsável por diminuir o custo de produção para o capitalista e este o repassaria para os preços.

\footnotetext{
37 Deve-se evidenciar que Prebisch não foi o único a perceber esse processo. Hans Singer, economista da ONU, sediado em Nova York, chegou a conclusões semelhantes quase à mesma época. Por conta dessa constatação de ambos os autores, os efeitos distintos do comércio internacional ficaram conhecidos como a tese "Prebisch-Singer". Recomenda-se Singer (1950).
} 
A partir da crítica à teoria neoclássica, Prebisch ([1949] 2000) avançou no entendimento da deterioração dos termos de troca, de como isso se vinculava a uma relação centro-periferia, que seria permanente, caso não houvesse uma transformação dos países periféricos agrário-exportadores em países industrializados.

\section{Considerações finais}

É notável a similaridade entre a interpretação de Simonsen e a de Prebisch/Cepal. Ambas as análises partiram de uma crítica aos limites da teoria neoclássica. Além de realizarem essa crítica, Simonsen e Prebisch/Cepal discutiram uma outra abordagem, na qual fazia sentido dar importância ao setor industrial em economias subdesenvolvidas e a políticas protecionistas do Estado para o seu avanço.

Também foi possível observar que tanto Simonsen quanto Prebisch/Cepal identificaram os prejuízos históricos sofridos por países agrícolas por meio dos termos de troca no comércio internacional com os países industrializados; a importante relação que deve existir entre indústria e agricultura, e, por fim, a interpretação de que uma industrialização nacional pudesse resolver os principais problemas do subdesenvolvimento.

Essas semelhanças permitem afirmar o pioneirismo de Simonsen neste debate, senão na América Latina, ao menos no Brasil. Ainda no ano de 1928, como pontuado neste artigo, ele defendia a industrialização brasileira e um regime protecionista como meio para se atingir tal fim. Em relação à desigualdade no comércio internacional, Simonsen tratou deste problema no Brasil no I Congresso de Economia, realizado em 1943. Em 1948, chegou a citar a desvantagem "nos termos de troca" dos países exportadores de produtos primários frente aos países industrializados e exportadores de bens manufaturados.

A recuperação dessas interpretações mostrou como Simonsen foi a principal voz dentro do país que ecoava boa parte do que então posteriormente à sua morte seria conhecido somente como parte importante das contribuições da Cepal para toda a América Latina.

Simonsen cometeu equívocos. Não identificou, por exemplo, a impossibilidade de um país como o Brasil repetir trajetórias de outras nações. 
Também Ihe faltaram questionamentos sobre os limites de um processo de industrialização para o desenvolvimento de países atrasados, não só por determinantes internos, como também por determinantes externos, como os bloqueios do imperialismo a esse processo.

Certamente, ele não viveu para acompanhar os desdobramentos da industrialização no Brasil e observar distanciamentos que este processo teve de um projeto nacional de fato, que englobasse a sociedade como um todo para uma "marcha civilizatória". No Brasil, apesar de ter ocorrido uma industrialização, não houve o desenvolvimento nacional.

\section{REFERÊNCIAS}

ANAIS do I Congresso Brasileiro de Economia. Volume 1, Rio de Janeiro, Oficina Gráfica Mauá, 1943.

ANAIS do I Congresso Brasileiro de Economia. Volume 2, Rio de Janeiro, Oficina Gráfica Mauá, 1944.

ANAIS do I Congresso Brasileiro de Economia. Volume 3, Rio de Janeiro, Oficina Gráfica Mauá, 1946.

BIELSCHOWSKY, R. (1988) Pensamento Econômico Brasileiro: o ciclo ideológico do desenvolvimentismo. 4. ed. Rio de Janeiro: Contraponto, 2000.

BRAGA, M. B. Raul Prebisch e o livre comércio: as origens do pensamento econômico estruturalista. Prolam, v. 1, 2009.

CEPAL (1955). Introdução à técnica de planejamento. In: BIELSCHOWSKY, R. (Org.) Cinquenta anos de pensamento na Cepal. Rio de Janeiro: Record, Vol.1, 2000.

COUTO, J. M. O pensamento desenvolvimentista de Raúl Prebisch. Economia e Sociedade, Campinas, v. 16, n. 1 (29), p. 45-64, abr., 2007.

DOSMAN, E. Raúl Prebisch (1901-1986): a construção da América Latina e do Terceiro Mundo. Rio de Janeiro: Contraponto, 2011.

FERRAZ, M. A FIESP e a Conferência das Classes Produtoras. Revista Industrial de S. Paulo, Ano I, Maio de 1945, No 6, p.13-15.

FURTADO, C. (1959) Formação Econômica do Brasil. São Paulo: Editora Nacional, 1984. . A Fantasia organizada. Rio de Janeiro: Paz e Terra, 1985.

. Os ares do mundo. Rio de Janeiro: Paz e Terra, 1991. 
. Entrevista. Realizada por Rosa Maria Vieira. Rio de Janeiro: Revista História Oral, UFRJ, n $^{\circ}$ 7, 2004, pp. 21-40.

GURRIERI, A. La obra de Prebisch en la Cepal. México: Fondo de Cultura Económica, 1982.

HAMILTON, A. (1791) Relatório sobre as manufaturas. Rio de Janeiro: Solidariedade Iberoamericana, 1995.

HIRSCHMAN, A. Ideologias do desenvolvimento econômico na América Latina. In: HIRSCHMAN A. (Org.) Monetarismo vs. Estruturalismo: um estudo sobre a América Latina. Rio de Janeiro: Lidador, 1967.

HOBSBAWM, E. Era dos Extremos: o breve século XX, 1914-1991. São Paulo: Companhia das Letras, 1995.

JURGEnFELD, V. F. Teoria do subdesenvolvimento de Celso Furtado: criatividade e contraposição a interpretações neoclássicas. Campinas: 2018. Tese (Doutorado) - Instituto de Economia - Universidade Estadual de Campinas.

LIST, F. (1841) Sistema Nacional de Economia Política. São Paulo: Nova Cultural, 1986.

LOVE, J. L. Las fuentes del estructuralismo latino-americano. Desarrollo Económico, Vol. 36, No. 141 (Apr. - Jun., 1996), p. 391-402.

MANOILESCU, M. Theoria do proteccionismo e da permuta internacional. São Paulo: Centro das Indústrias do Estado de São Paulo, 1931.

O’CONNELL. O retorno da vulnerabilidade e as reflexões iniciais de Raúl Prebisch sobre "el ciclo económico argentino”. Economia e Sociedade. Campinas, (16): 1-26, jun 2001.

PINTO, A. (1970). Natureza e implicações da "heterogeneidade estrutural" da América Latina. In: BIELSCHOWSKY, R. (Org.) Cinquenta anos de pensamento na Cepal. Rio de Janeiro: Record, Vol.2, 2000.

PREBISCH, R. (1949). O desenvolvimento econômico da América Latina e alguns de seus problemas principais. In: BIELSCHOWSKY, R. (Org.) Cinquenta anos de pensamento na Cepal. Rio de Janeiro: Record, Vol.1, 2000.

(1950) Crecimiento, desequilibrio y disparidades: Interpretación del proceso de desarrollo económico. In: GURRIERI, A. La obra de Prebisch en la Cepal. México: Fondo de Cultura Económica, 1982.

. (1957). O mercado comum latino-americano. In: BIELSCHOWSKY, R. (Org.) Cinquenta anos de pensamento na Cepal. Rio de Janeiro: Record, Vol.1, 2000.

. Hacia una dinámica del desarrollo latinoamericano. México: Fondo de Cultura Económica, 1963. 
Change and development: Latin America ${ }^{e e}$ sreat task. Relatório de Raúl $\begin{array}{llll}\text { Prebisch na } & \text { Unctad, } & \text { Disponível }\end{array}$ em:<https://repositorio.cepal.org/bitstream/handle/11362/31061/S33898P922TDG.pdf?seque nce $=1>$. Acesso em outubro de 2018

. Prefácio. In: RODRÍGUEZ, O. A teoria do subdesenvolvimento da Cepal. Rio de Janeiro: Forense, 1981.

Cinco etapas de mi pensamiento sobre el desarrollo. Comercio Exterior, vol. 37, n. 5, México, maio/1987, 345-352 pp.

RICARDO, D. (1817) Princípios de economia política e tributação. São Paulo, SP: Nova Cultural, 1988.

RODRIGUES, C. H. L. A questão do protecionismo no debate entre Roberto Simonsen e Eugênio Gudin. Dissertação de Mestrado. Instituto de Economia/Unicamp, 2005.

Roberto Simonsen e Eugênio Gudin: origem de um debate ainda não superado na economia brasileira. Cadernos do Desenvolvimento, Rio de Janeiro, vol. 13, n. 23, p. 129154, jul.-dez., 2018.

RODRÍGUEZ, O. A teoria do subdesenvolvimento da Cepal. Rio de Janeiro: Forense, 1981.

SIMONSEN, Roberto. (1928) Orientação industrial brasileira. In: - Evolução Industrial do Brasil e outros estudos; seleção, notas e bibliografia de Edgard Carone. São Paulo: Editora Nacional e Editora da USP, 1973.

Aspectos da política econômica nacional. In: Discursos pronunciados na Câmara Federal dos Deputados, 11 de Setembro de 1935.

. (1939) Evolução industrial do Brasil. In: Evolução Industrial do Brasil e outros estudos; seleção, notas e bibliografia de Edgard Carone. São Paulo: Editora Nacional e Editora da USP, 1973.

. Ensaios Sociais, Políticos e Econômicos. São Paulo: FIESP, 1943.

(1943) Alguns aspectos da política econômica mais conveniente ao Brasil no período do após-guerra. In: Evolução Industrial do Brasil e outros estudos; seleção, notas e bibliografia de Edgard Carone. São Paulo: Editora Nacional e Editora da USP, 1973.

. (1944) A planificação da economia brasileira. In: A controvérsia do planejamento na economia brasileira; coletânea da polêmica Simonsen X Gudin, desencadeada com as primeiras propostas formais de planejamento da economia brasileira ao final do Estado Novo. Rio de Janeiro: IPEA/INPES, 1977.

. Congresso brasileiro da indústria. Revista Industrial de S. Paulo, Ano I, Janeiro de $1945, \mathrm{~N}^{\circ} 2$, p.12-13. 
. (1948) "Memorandum". In: Anais do Conselho Econômico da Confederação Nacional da Indústria dos anos de 1947, 1948 e 1949. Rio de Janeiro, 1951.

SINGER, H. The distribution of gains between investing and Borrowing countries. America Economic Review, maio, 1950, p. 472-499.

SMITH, A. (1776) A riqueza das nações: investigação sobre sua natureza e suas causas. São Paulo, SP: Abril, 1983.

VÁSQUEZ, J. F. N. (1957) Inflação e desenvolvimento econômico no Chile e no México. . In: BIELSCHOWSKY, R. (Org.) Cinquenta anos de pensamento na Cepal. Rio de Janeiro: Record, Vol.1, 2000.

\section{NOTAS DE AUTOR}

\section{CONTRIBUIÇÃO DE AUTORIA}

Carlos Henrique Lopes Rodrigues - Concepção. Coleta de dados, Análise de dados, Elaboração do manuscrito, revisão e aprovação da versão final do trabalho.

Vanessa Follmann Jurgenfeld - Concepção e elaboração do manuscrito. Coleta de dados Participação ativa da discussão dos resultados; Revisão e aprovação da versão final do trabalho.

\section{FINANCIAMENTO}

Não se aplica.

\section{CONSENTIMENTO DE USO DE IMAGEM}

Não se aplica

\section{APROVAÇÃO DE COMITÊ DE ÉTICA EM PESQUISA}

Não se aplica.

\section{CONFLITO DE INTERESSES}

Não se aplica

\section{LICENÇA DE USO}

Este artigo está licenciado sob a Licença Creative Commons CC-BY. Com essa licença você pode compartilhar, adaptar, criar para qualquer fim, desde que atribua a autoria da obra.

\section{HISTÓRICO}

Recebido em: 03-07-2019

Aprovado em: 06-02-2020 